From the Field

\title{
Graphic Design and Instructional Methods: An Action Research Study
}

\section{David E. Gorski}

Technology and engineering education is filled with so many varied topics that it is almost impossible to break them into grade-level courses. As a result, courses are often mixed with all grade levels and all types of learners. On rare occasions, one course section pops into the schedule that is all one level. When this occurs, it may become necessary to reevaluate the practices that have been implemented in the classroom related to instruction, discipline, and policy. For this study, the population of graphic design students consisted of primarily freshman students.

In this case, the researcher was faced with an entire section of graphic design with primarily freshman students. In the past, there had been freshmen mixed into other sections without any problems. However, this class posed an interesting problem: traditional instructional methods were not working. This section of mostly freshman students was falling behind the usual curricular pace for the class. They were struggling to work with the independence that they are granted as high school students. They were also struggling with following the directions given to them in the manner traditional for this course, which was backed by past practices. With this new demographic, it became necessary to evaluate alternative instructional practices in relation to freshman students.

The typical collegiate style in which instruction has been given in my classroom has been successful in the past. However, this approach, in which all expectation is put on the learner, was not proving successful in a classroom filled primarily with freshmen students who have not fully made their transitions out of middle school mentality. Therefore, I decided to look into scaffolded instructional models as a means to increasing student understanding and mastery.

\section{Literature Review}

The concept of scaffolded instruction (Bruner, 1975) stems from Lev Vygotsky's concept of the "Zone of Proximal Development" (ZPD), which is the area within the students' intellectual ability between where they can act independently and where they need instruction or help to achieve the goal (Shabani, Khatib, \& Ebadi. 2010). Scaffolded instruction allows the educator to create a support system for the student in order to move them through contend within their ZPD. Scaffolded instruction can be thought of exactly as scaffolding while building. You will always need support if you are trying to work over 
your head our beyond your reach. In 1997, Hogan and Pressley summarized the preexisting literature into eight essential scaffolding guidelines:

- "Pre-engagement" (i.e., selecting tasks appropriate for students and curricular goals);

- "Establishing a shared goal";

- "Actively diagnosing the understandings and needs of the learner" ( $p$. $82)$;

- "Providing tailored assistance";

- "Maintaining pursuit of the goal";

- "Giving feedback";

- "Controlling for frustration and risk"; and

- "Assisting internalization, independence, and generalization to other contexts" (p. 83).

Following these guidelines, not necessarily in a set sequence, will allow an educator to reach students at all levels and help facilitate growth in both high and low achieving students. Some potential "challenges and cautions for scaffolding instruction" (Larkin, 2002, p. 4) are as follows.

- Use scaffolding as needed. Not all students will need it in every lesson.

- Know your curriculum and your students. This will allow you to identify problem areas ahead of time.

- Prepare prompts ahead of time.

- Have patience.

Scaffolded instruction is a powerful tool that can allow an instructor to make accommodations and modifications to pre-established curriculum in order to maximize student achievement.

\section{Action Research Questions}

The purpose of this study was to answer the following two questions.

- Does scaffolding instruction in a graphic design class improve achievement?

- Does scaffolding instruction in a graphic design class help keep students on the curricular timeline?

The intent was to take current practices and investigate a new instructional method to help a class of mostly freshman succeed. Students' completion dates and grades were compared to previous years' records in order to show the need for this study. Then, after new instructional methods were integrated and a new batch of assessments were completed, they were compared with the grades of freshmen in the mixed-level classes from the previous semester to establish the effectiveness of the modifications.

\section{Methodology}

This class consisted of 15 students, six of whom were freshmen. This may not seem like a high concentration; however, given the usual demand for classes, 
it is unlikely that students will get into these classes until they have more free slots in their schedule. At the beginning of the semester, there were eight freshmen in the class, but two were removed for scheduling reasons. The previous semester, there were only six freshman in total across all three sections of the course.

Data were generated by modifying an introductory lesson in Adobe Illustrator ${ }^{\mathbb{B}}$ about perspective (Appendix A). This tool is a very powerful way of adding visual interest to artwork. Unfortunately, mastery of this tool is very difficult because small mistakes or additions could ruin the entire project. Students were given an instructional booklet, a modified tutorial that was prepared to increase student understanding. This packet replaced our traditional demonstration and lecture method for this lesson. With the introduction of the packet as well as direct instruction, guided practice, and teacher demonstrations, we built a true scaffold of support.

The lesson was delivered with supports to all students in the class, and after a few days, the students submitted their projects for grading. The resulting projects, although simple, demonstrate mastery of the various tools and components in Adobe Illustrator to create a 3D cityscape. The project grades were compared with those of freshman students in the Semester 1 class who did not receive the same scaffolded instruction that the Semester 2 students did. Fortunately, the sample sizes where the same for each group: Semester 1 had a total of six freshmen from the three course sections, and Semester 2 had six freshman in the course.

\section{Data Analysis}

After all the data were collected and compiled, conclusions could be drawn. The data were compared across four dimensions: passing grade on the assignment, correct components of the buildings, correct coloring of the buildings, and assignments submitted in the correct format.

The data for the Semester 1 students, who received traditional non-scaffolded instruction, are as follows. Of the six freshmen spread across three sections of the graphic design course, $83 \%$ completed the task with a passing grade. Only $33 \%$ of the students had all of the components of the buildings correct. This means that all buildings and windows were aligned perfectly in perspective as per the directions given. Only $16 \%$ of the students correctly colored the buildings as per the directions. Finally, only $50 \%$ of the students submitted their assignments in the correct format to our Google Classroom.

The data for the Semester 2 students, who received scaffolded instruction, are as follows. Of the six freshmen in the Semester 2 section, $100 \%$ completed the assignment with a passing grade. Of these students, $100 \%$ had all of the components of the buildings correct. However, only $83 \%$ of the students had the buildings colored correctly. Finally, 100\% of the students submitted their assignments in the correct format to our Google Classroom. 
The first data point (Figure 1), passing grades, marks a $17 \%$ increase from Semester 1 to Semester 2 students. This shows that scaffolding was beneficial for the freshmen students. Although a marginal increase, it still lends support for the use of scaffolding to improve student learning.

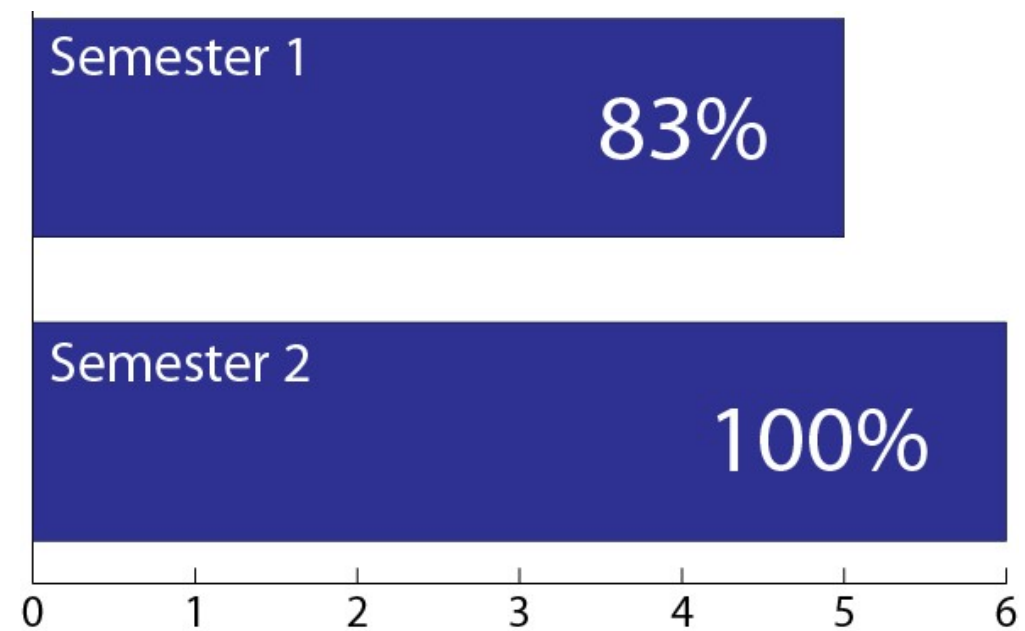

Figure 1. Number and percentage of students who completed the assignment with a passing grade.

The second data point (Figure 2), correct components of the buildings, marks a $67 \%$ increase in the students' ability to demonstrate mastery of the various tools and concepts in Illustrator required to create a cityscape in perspective. This point is the most critical to me. A student may or may not submit a finished assignment; however, if they can demonstrate mastery of the individual tools and techniques, then I know that they have developed an understanding of the program and what it is capable of. 
Windows Not In Perspective

Windows In Perspective

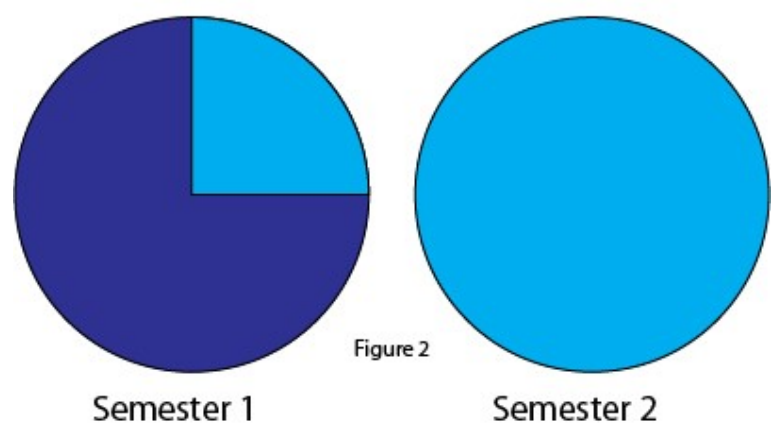

Figure 2. Correct components of the buildings: windows in perspective.

The third data point (Figure 3), correct coloring, marks a 66\% improvement in the students' ability to use the various color tools and create complex gradients to enhance their designs. The ability to complete such a complex task and create these gradients shows that the students can follow a complex set of directions perfectly to achieve their goal.

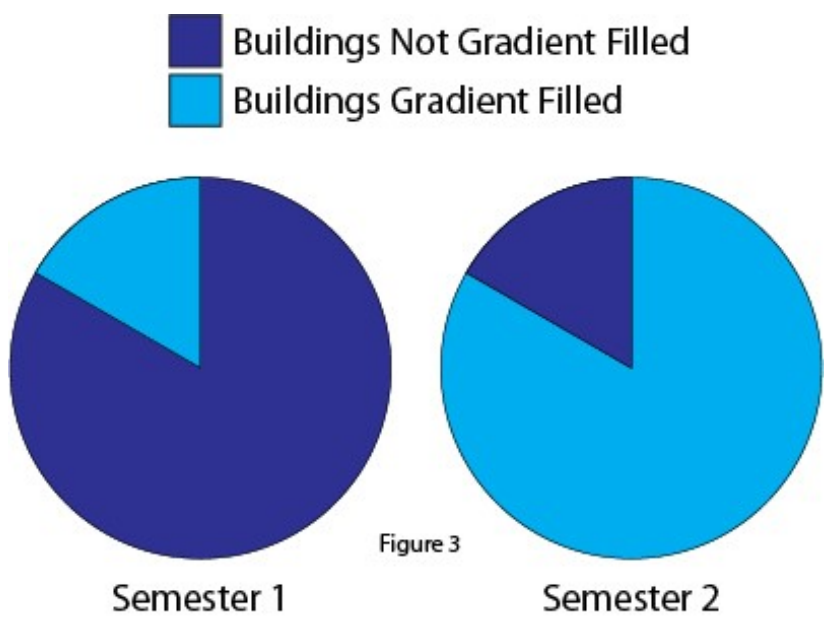

Figure 3. Correct coloring: building are gradient filled. 
The fourth and final data point (Figure 4), correct submission, marks a $50 \%$ improvement. Having students submit the assignments correctly is important for any teacher. Having file format and naming convention correct is vital when dealing with many files that all look the same. This data point also takes into consideration the timeline of this project.

\section{Projects Not Submitted Correctly Projects Submitted Correctly}

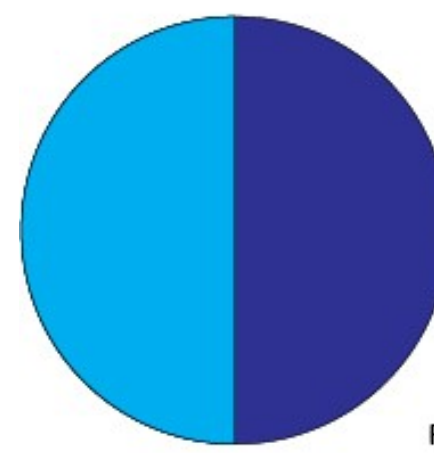

Semester 1
Figure 4

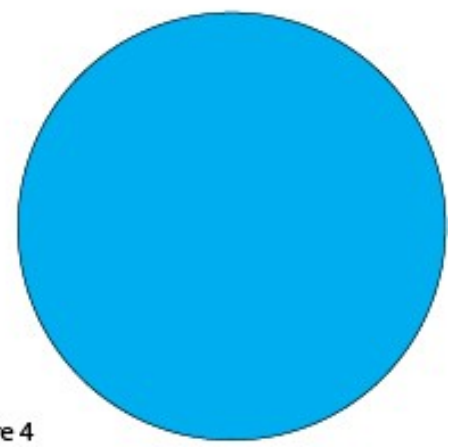

Semester 2

Figure 4. Correct submission of projects.

In addition to the above data points, the assignments submitted were of a higher quality than the previous sections of the course. Although this observation was more subjective in nature, it showed that students were referencing prior content and putting more effort into their assignments.

\section{Summary and Conclusions}

In summary, the freshmen students in this graphic design class reacted positively across all measurable indicators. The students were able to use the scaffolded lesson to complete the assignment to expectations. The data show that for freshmen, the inclusion of scaffolding has drastically improved the results at the end of the lesson. Students have produced work in the same timeframe as Semester 1 while improving in all measurable areas.

Student success has shown that although the traditional methods of instruction have worked with other grade levels in years past, scaffolded instruction had a positive effect on freshmen of all achievement levels. Because $100 \%$ of Semester 2 students submitted assignments correctly, set up buildings correctly, and received passing grades, it is clear that the level of instructional support that was provided was appropriate for the lesson. 


\section{Future Actions and Directions}

Looking towards the future, there are a few changes that I would like to make based on the data collected. I would like to collect data from a larger sample of freshmen students to ensure that the supports are what increased success and that this was not an abnormality. I would also like to modify a more base-level introductory lesson to see if getting students on a scaffolded structure earlier in the course will build upon success as the semester progresses.

Next steps for researching will involve restructuring content and lessons in order to provide supports at a lower level. Along with the restructure, I will need to create a new series of rubrics and grading materials in order to create more data points to monitor student progress. Finally, I need to develop some sort of mode for student feedback. Whether that means direct responses on each assignment or anonymous surveys, I need student feedback in order to help them succeed.

An interesting side effect of this research has been increased interest in direct tutorial based instruction from students. Some students have asked for both simple and in-depth tutorials for all aspects of the graphic design class. I anticipate that delving deeper into these requests will increase student interest and hopefully help students gain a deeper interest in the topic.

\section{References}

Bruner, J. S. (1975). The ontogenesis of speech acts. Journal of Child Language, 2(1), 1-19. doi:10.1017/S0305000900000866

Hogan, K., \& Pressley, M. (1997). Scaffolding scientific competencies within classroom communities of inquiry. In K. Hogan \& M. Pressley (Eds.), Scaffolding student learning: Instructional approaches and issues (pp. 74107). Cambridge, MA: Brookline Books.

Larkin, M. (2002) Using scaffolded instruction to optimize learning. Retrieved from ERIC database. (ED474301)

Shabani, K., Khatib, M., \& Ebadi, S. (2010). Vygotsky's Zone of Proximal Development: Instructional implications and teachers' professional development. English Language Teaching, 3(4), 237-248. doi:10.5539/elt.v3n4p237

\footnotetext{
About the Author

David E. Gorski (gorskid@stafford.k12.ct.us) is a Technology and Engineering Education Teacher at Stafford High School in Stafford Springs, Connecticut.

A link to David's instructional unit is linked under the actual article at http://scholar.lib.vt.edu/ejournals/JTE/.
} 